\title{
Serum anti-Müllerian hormone as a predictive marker of polycystic ovarian syndrome
}

This article was published in the following Dove Press journal:

International Journal of General Medicine

| November 201 |

Number of times this article has been viewed

\section{Sergio Parco' \\ Caterina Novelli ${ }^{2}$ \\ Fulvia Vascotto' \\ Tanja Princi ${ }^{2}$}

'Institute for Maternal and Child Health, IRCCS Burlo Garofolo, Trieste, Italy; ${ }^{2}$ Department of Life Sciences, University of Trieste, Garofolo, Trieste, Italy

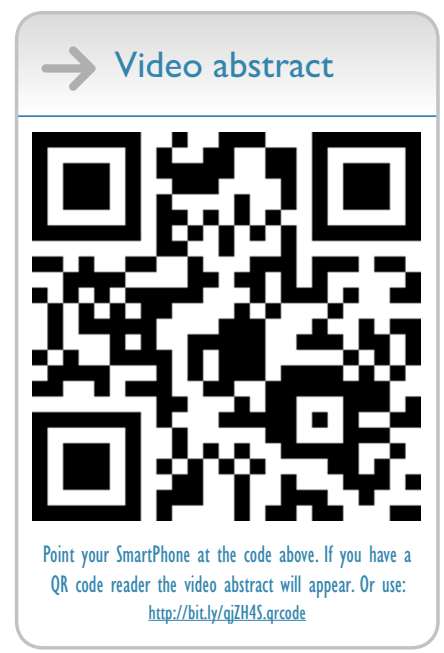

Correspondence: Sergio Parco Institute for Maternal and Child Health, Garofolo, Trieste, Italy

Tel +39 403785332

$\mathrm{Fax}+39403785210$

Email parco@burlo.trieste.it
Background: The anti-Müllerian hormone (AMH) is a dimeric protein secreted by the female ovaries and has two fundamental roles in follicle genesis. It delays the entrance of the primordial follicle into the pool of follicles in growth and diminishes the sensitivity of the ovarian follicle towards follicle-stimulating hormone (FSH). The purpose of this work was to study the AMH (nv $2.0-6.8 \mathrm{ng} / \mathrm{mL}$ ) as a marker during assisted reproductive technology (ART), in order to identify cases of infertility due to polycystic ovarian syndrome (PCOS). This syndrome affects $10 \%$ of women with infertility problems, and a new biological marker could be useful to general practitioners of internal medicine to help generate the suspicion of PCOS so that they can refer the patient to the gynecologist for confirmation.

Methods: This study enrolled 236 patients aged 26-46 years undergoing assisted reproductive technology at the Institute for Maternal and Child Health, Trieste, Italy. On the third day of the ovarian cycle, the patients were given doses of AMH, FSH, and luteinizing hormone ( $\mathrm{LH}$, in cases of AMH $>2.0-6.8 \mathrm{ng} / \mathrm{mL}$ ). A control pelvic ultrasound was also carried out.

Results: We identified 57 patients who were starting in vitro fertilization or embryo transfer with AMH values within the normal range $(3.64 \pm 1.51 \mathrm{ng} / \mathrm{mL}), 77$ with values below normal $(1.38 \pm 0.32 \mathrm{ng} / \mathrm{mL})$, and 96 cases with undetectable values of AMH. Six patients had very high AMH levels $(10.0 \pm 2.28 \mathrm{ng} / \mathrm{mL})$ and, of these, five were found to have PCOS on pelvic ultrasound examination $(P<0.05)$. We also found inverse correlations between AMH levels and age $(r=-0.52)$ and between AMH and FSH levels $(r=-0.32)$.

Conclusion: In clinical practice it is common to encounter patients who turn to medicine in search of a cure for female infertility. In our experience, AMH two or three times the normal amount $(10 \pm 2.28 \mathrm{ng} / \mathrm{mL})$, is a good indication of PCOS and infertility.

Keywords: anti-Müllerian hormone, serum level, follicle development, polycystic ovarian syndrome, predictive marker

\section{Introduction}

Anti-Müllerian hormone (AMH), also known as Müller inhibiting factor or Müller inhibiting substance, is a glycoprotein formed from two identical subunits, each with a molecular weight of $72 \mathrm{kDa}$. The hormone is part of the growth factor family, which includes 35 different peptide structures, including inhibin, activin, growth differentiation factor, and bone morphogenic protein. ${ }^{1}$ Up until a few years ago, AMH was known mainly for its role in the differentiation of male sexual characteristics. ${ }^{2,3}$

$\mathrm{AMH}$ is not secreted in the female embryo, allowing development of the female sexual organs, starting from the Müller ducts which do not regress, although they differ in the uterus, fallopian tube, and upper part of the vagina. Expression of the hormone 
in women is different at various stages of life, and starts to be detected at week 36 of gestation. Its concentration reaches a maximum during puberty, begins to decrease in adulthood, and disappears completely following the menopause. AMH, produced from the granulosa cells of the primary follicles, reaches maximum expression in the preantral follicles, with lesser secretion by the greater antral follicles. At this point, growth starts to become dependent on follicle-stimulating hormone (FSH). The data suggest that $\mathrm{AMH}$ is a factor in regulation during the initial recruitment and cyclical recruitment phases leading to selection of the dominant follicle, and that it has a potential autocrine and paracrine role in follicular development in the female ovaries.

After a period of optimal fertility at age 18-30 years, oocyte quality diminishes in parallel with a progressive loss of follicles. In women with normal ovulation, serum levels of AMH slowly increase, reaching a peak during puberty and then progressively diminishing with the passage of time. Their lessening is detected by markers of ovarian age. Moreover, recent studies have shown that AMH is correlated with the number of small antral follicles. This observation supports the hypothesis that serum levels of AMH can reflect the state of the ovarian follicles better (given its relative stability during the entire cycle) than the more usual hormonal markers (FSH, luteinizing hormone [LH], estradiol, and inhibin B), and demonstrates how AMH can be a favorable candidate as a marker of the ovarian reservoir. ${ }^{4-6}$

\section{Infertility and polycystic ovary syndrome. Meaning of anti-Müllerian hormone}

Reproductive behavior has changed dramatically in the last century, and it is important to be able to identify loss of fertility in a woman as early as possible. More and more women are now delaying pregnancy to a more advanced age, when the quality and amount of ovarian follicles begins to decrease. The first sign of aging is increased levels of FSH at the age of 35-40 years, when the menstrual periods tend to shorten. Therefore, determining ovarian age is important for patients in whom treatment with in vitro fertilization is proposed, keeping in mind that the probability of pregnancy and subsequent birth of a child gradually diminishes from the age of 37-38 years onwards.

From this point of view, AMH has been identified and proposed for evaluation of responses in patients undergoing assisted reproductive technology. It is now a potential candidate for inclusion in the clinical report, in order to be able to construct a strategy which is targeted and personalized to the characteristics of the patient, and able to increase the benefits of treatment from the physiological, psychological, and economic points of view. ${ }^{7-9}$

Numerous studies have advocated the use of AMH in assisted reproductive technology as a noninvasive test in order to estimate the antral follicle count. ${ }^{10,11}$

$\mathrm{AMH}$ is now proposed as a hormonal test in the study of feminine infertility and in the diagnosis of PCOS. The diagnosis depends on two of the following criteria: clinical and/or biochemical evidence of hyperandrogenism (with exclusion of other causes of excess androgen), oligo or anovulation, and polycystic ovaries (European Society of Human Reproduction and American Society for Reproductive Medicine, Consensus Conference, Rotterdam, 2003). ${ }^{12,13}$ Such data lead us to conclude that inclusion of serum AMH levels in routine tests for patients undergoing assisted reproductive technology is useful, both quantitatively and qualitatively, not only in the study of patient responses to clinical treatment for infertility, but also in clinical assessment. ${ }^{14-20}$

\section{Use of anti-Müllerian hormone}

Numerous tests and markers are used in order to identify pathologies involving the ovaries. Amongst these are exclusion serum markers of other endocrinopathies (prolactin, thyroid stimulating hormone, 17-hydroxyprogesterone), confirmation of serum markers of ovarian pathology (FSH, LH, estradiol, inhibin B), invasive scan markers (transvaginal or laparoscopic ultrasound for antral follicle count) and, over the last few years, AMH levels. There are also other confirmation and monitoring serum tests for PCOS (androstenedione, testosterone, free testosterone, dehydroepiandrosterone). This diagnosis will not only render possible a targeted and personalized therapy in order to achieve a greater probability of a positive outcome of treatment, but will also avoid potential harmful effects of treatment, that could eventually preclude assisted reproduction altogether.

\section{Aim}

In this study, we evaluated the value of serum analysis of $\mathrm{AMH}$ as a diagnostic test in patients undergoing assisted fertility, in order to diagnose PCOS prior to treatment. The purpose was to identify a cost-effective, noninvasive clinical method for assessing ovarian pathology, which would also reduce psychological stress for the patient. AMH can be measured on any day of the cycle, because there are no fluctuations and it has low cyclical interindividual or intraindividual variability. 
Table I Suggested definitions according to AMH values for the hormone therapy by ART (IRCCS Burlo Garofolo)

\begin{tabular}{lllll}
\hline $\begin{array}{l}\text { AMH nv } \\
\mathbf{2 . 0} \mathbf{6 . 8} \mathbf{~ n g / m L}\end{array}$ & $\begin{array}{l}\text { Normal responders } \\
\text { mean }^{\mathbf{a}}\end{array}$ & $\begin{array}{l}\text { Poor responders } \\
\text { mean }^{\mathbf{b}}\end{array}$ & $\begin{array}{l}\text { No responders } \\
\text { mean }^{\mathbf{c}}\end{array}$ & $\begin{array}{l}\text { POCS } \\
\text { mean }^{\mathbf{d}}\end{array}$ \\
\hline Values $\mathrm{ng} / \mathrm{mL}$ & 3.64 & 1.38 & 0.4 & 10.0 \\
Years & 35 & 36.9 & 37.5 & 31 \\
Patient number & 57 & 77 & 96 & 6 \\
Pelvic ultrasound & Normal & Normal & Normal & Pathological \\
\hline
\end{tabular}

Notes: ${ }^{a}$ Normal responders: patients with ovarian reserve and possibilities of pregnancy by ART; ${ }^{b}$ poor responders: patients with reduction of ovary reserve and difficult therapeutic response; 'no response: patients to send to IVF or FIVET; ${ }^{d}$ patients with PCOS.

Abbreviations: ART, assisted reproductive technology; IVF, in vitro fertilization; FIVET, in vitro embryo transfer; nv, normal value; PCOS, polycystic ovary syndrome.

\section{Materials and methods}

The study was carried out on 236 serum samples taken from women aged 26-46 years and scheduled for exogenous gonadotrophin treatment for infertility at the Institute for Maternal and Child Health, Burlo Garofolo, Trieste, between September 2010 and June 2011. All patients signed an informed consent form before entering the study, which was approved by the ethics committee at our institution.

The serum samples were centrifuged to separate the cellular component. The sample centrifugation for 5', as described in the manufacturer's instructions, was done to remove residual fibrin and cellular matter, prior to storage. Lipemic or hemolyzed samples have been eliminated. The serum was stored at $2^{\circ} \mathrm{C}-8^{\circ} \mathrm{C}$ for up to 24 hours and was then frozen at $-20^{\circ} \mathrm{C}$. The confidence limits for $\mathrm{AMH}$ controls were printed on the control vial labels and intra- and inter-test precision was within two standard deviations ( $\pm 2 \mathrm{SD})$.

Measurement of AMH levels was carried out on the third day of the ovarian cycle using an enzyme-linked immunosorbent assay (Beckman Coulter, Immunotech, DSL Diagnostic System Laboratories, Marseille, France). This quantitative, specific, and sensitive technique allows measurement of small amounts of molecules present in biological samples. Moreover, it is possible to analyze a high number of samples in a short space of time, as a result of being able to use microplates. It is based on a colorimetric system, with the intensity of color being directly proportional to the concentration of the antigen, which is measured by spectrophotometry.

The field of measurement comprises concentration of the analyte sensitivity to the concentration of the highest calibrator standard, from $0.14 \mathrm{ng} / \mathrm{mL}$ to $21 \mathrm{ng} / \mathrm{mL}$. The precision is given by an intratest and an intertest, with respective variation coefficients of $12.3 \%$ and $14.2 \%$, respectively. The instrument used for analysis in the enzymelinked immunosorbent assay was a semiautomatic spectrophotometer (Pantech, New York, NY). The enzyme-linked immunosorbent assay used was a typical sandwich test, the peculiarity of which concerns a second biotinylated monoclonal antibody directed against the antigen and conjugated with the enzyme streptavidin and horseradish peroxidase. Streptavidin is a purified tetrameric protein of bacterial origin (Streptomyces avidinii). In order to estimate the AMH concentration in the study samples, a calibration curve for interpolation was constructed, using standard AMH samples with

Table 2 IRCCS Burlo Garofolo normal values vs others AA

\begin{tabular}{|c|c|c|c|c|c|c|c|}
\hline Authors & Manufacturers & $\begin{array}{l}\text { Normal values } \\
\text { (ng/mL) }\end{array}$ & $\begin{array}{l}\text { Patient age } \\
\text { (years) }\end{array}$ & $\mathbf{N}$ & $\begin{array}{l}\text { PCOS values } \\
\text { (ng/mL) }\end{array}$ & $\begin{array}{l}\text { Patient age } \\
\text { (years) }\end{array}$ & $\mathbf{N}$ \\
\hline de $V e t^{30}$ & IC & 1.3 & $32 \pm 4$ & 41 & - & - & - \\
\hline Pigny ${ }^{12}$ & $\mathrm{BC}$ & 2.91 & 27 & 45 & 6.59 & 28 & 59 \\
\hline Franchin $^{31}$ & $\mathrm{BC}$ & 1.39 & 34 & 75 & - & - & - \\
\hline Eldar-Geva ${ }^{23}$ & $\mathrm{IC}$ & 1.6 & 30.7 & 23 & 4.2 & 29.8 & 29 \\
\hline La Marca ${ }^{6}$ & $\mathrm{BC}$ & $3.8 \pm 1.2$ & 21 & 12 & - & - & - \\
\hline Tsepelidis"I & DSL & 2.4 & 26.5 & 20 & - & - & - \\
\hline Wachs $^{24}$ & DSL & $2.13 \pm 0.4$ & 26.5 & 11 & $7.22 \pm 0.5$ & 26.5 & 16 \\
\hline Das $^{32}$ & DSL & 1.13 & 32 & 8 & 8.5 & 28 & II \\
\hline Nardo $^{14}$ & DSL & $2.4 \pm 1.7$ & $<40$ & 128 & $5.9 \pm 2.3$ & $<40$ & 37 \\
\hline Dorgan $^{33}$ & DSL & $3.5 \pm 4.08$ & 36.5 & 20 & - & - & - \\
\hline Arabzadeh ${ }^{17}$ & IC & 3.2 & 33 & 42 & 14.2 & 29 & 26 \\
\hline Falbo $^{34}$ & $\mathrm{BC}$ & $1.56 \pm 1.02$ & 28.17 & 10 & $3.92 \pm 1.62$ & 27.83 & 20 \\
\hline Parco 35 & $\mathrm{BC}$ & 1.22 & 36.4 & 86 & 10.0 & 31.05 & 5 \\
\hline
\end{tabular}

Abbreviations: BC, Beckman Coulter; IC, Immunotech Coulter; DSL, Diagnostic System Laboratory. 


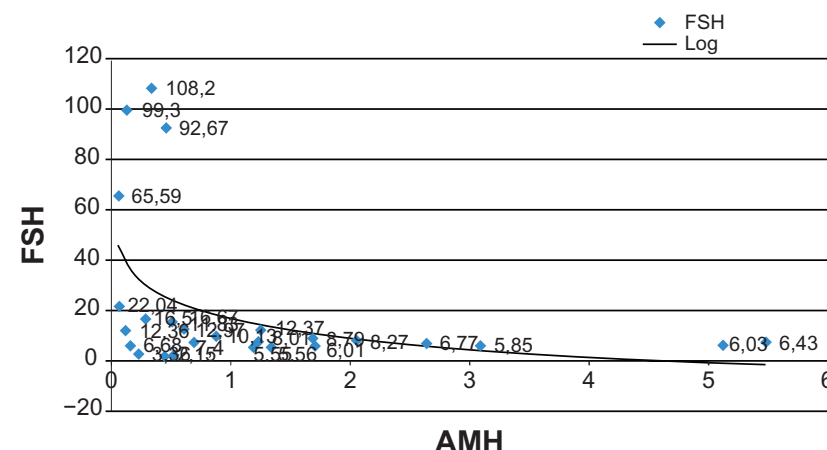

Figure I Graphic correlation: AMH vs FSH (IRCCS Burlo Garofolo). Abbreviations: $\mathrm{AMH}$, anti-Müllerian hormone; $\mathrm{FSH}$, follicle-stimulating hormone.

diverse absorbance concentrations (Pasquinelli and Porta, 1994), according to instructions supplied in the analysis kit. FSH levels for all the patients was measured, as well as LH (only in six patients with very elevated AMH levels) using an automated colorimetric method (Modular P, Elecsys). All patients underwent a baseline pelvic ultrasound.

\section{Results and discussion}

In this study, we analyzed 236 serum samples from patients aged 26-46 years who had been referred to our institution for medically assisted fertility in September 2010 to June 2011. We identified 57 patients who were starting in vitro fertilization or embryo transfer with AMH values within the normal range $(3.64 \pm 1.51 \mathrm{ng} / \mathrm{mL}), 77$ with values below normal $(1.38 \pm 0.32 \mathrm{ng} / \mathrm{mL})$, and 96 cases with undetectable values of AMH. Six patients had very high AMH levels (10.0 \pm $2.28 \mathrm{ng} / \mathrm{mL}$ ) and, of these, five were found to have PCOS on pelvic ultrasound examination $(P<0.05$; Table 1$)$.

We also compared our values with those reported in the literature. The published studies have reported the average values for patients who were part of control groups or had PCOS. Comparing the values that we obtained with those of other laboratories, it can be seen that the average values of controls are lower than those in patients with PCOS, confirming the validity of the test as an indicator of this syndrome (Table 2).

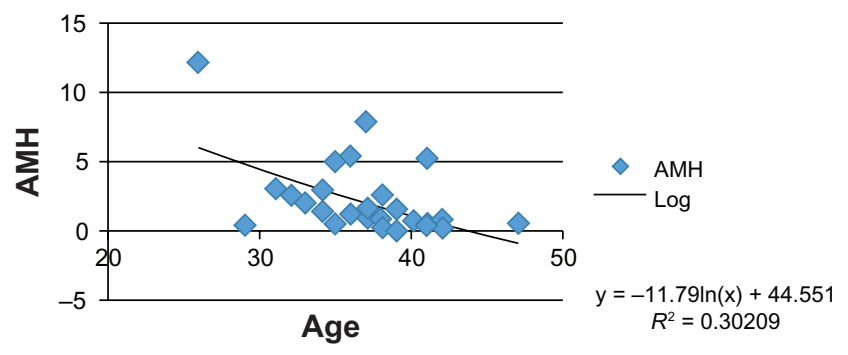

Figure 2 Graphic correlation: AMH vs age (IRCCS Burlo Garofolo). Abbreviation: $\mathrm{AMH}$, anti-Müllerian hormone.

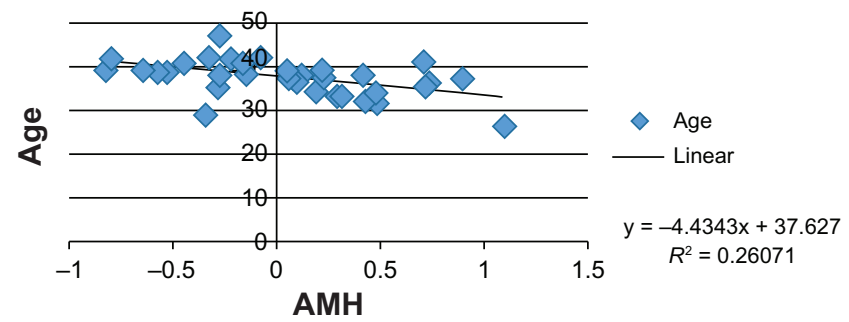

Figure 3 Graphic correlation: AMH and age (literature data). Abbreviation: $\mathrm{AMH}$, anti-Müllerian hormone.

Moreover, numerous studies have identified an inverse correlation between AMH levels, FSH levels, and patient age. Therefore, we attempted to confirm these correlations in our group of patients and FSH levels were also measured in serum samples, showing an average value of $8.53 \mathrm{mIU} / \mathrm{mL}$ (follicular phase normal range $3.5-12.5 \mathrm{mIU} / \mathrm{mL}$ ) (Figures 1-3).

The cost-effective dosage of AMH is similar to that of other hormones, such as FSH and LH.

\section{Conclusion}

Many studies published in recent years have demonstrated that the concentration of AMH is 3-4 times higher in patients affected by PCOS than in patients without the disease. There are two hypotheses to explain this finding. One is that the follicles are transformed into cysts when they are at the preantral or antral stage, and remain at this stage and continue to secrete the hormone, and the other is that granulosa cells secrete a greater concentration of AMH, detectable at the follicular level.

In our case histories, the changes in reproductive state and AMH levels are confirmed by levels of FSH and LH. This inverse correlation has been found in many studies in the literature, and is confirmed by the present study. ${ }^{21-25}$

Our data emphasize that AMH can be used to identify PCOS and is a reliable marker of infertility associated with patient age and other hormonal tests, such as FSH, because it is influenced by the menstrual cycle, or identification by means of invasive tests such as transvaginal or laparoscopic ultrasound for follicular count and residual ovarian capacity.

In conclusion, AMH is confirmed as a useful test to study folliculogenesis and ovarian potential in various situations of infertility and for identification of PCOS, to avoid the possibility of subjecting patients at risk to ineffective assisted reproductive technology, and using in vitro fertilization or in vitro embryo transfer only after careful clinical assessment. ${ }^{26-35}$

\section{Disclosure}

The authors report no conflicts of interest in this work. 


\section{References}

1. Knight PG, Glister C. TGF-beta superfamily members and ovarian follicle development. Reproduction. 2006;132:191-206.

2. Durlinger A, Gruijters M, Kramer P, et al. Anti-müllerian hormone inhibits initiation of primordial follicle growth in the mouse ovary. Endocrinology. 2002;143:1076-1084.

3. Molina P. Endocrine Physiology. 3rd edition. McGraw-Hill Medical Companies: New York; 2010:215-253.

4. Broekmans FJ, Visser JA, Laven JS, Broer SL, Themmen AP, Fauser BC. Anti-Müllerian hormone and ovarian dysfunction. Trends Endocrinol Metab. 2008;19:340-347.

5. Winkler N, Bukulmez O, Hardy DB, Carr BR. Gonadotropin releasing hormone antagonists suppress aromatase and anti-Müllerian hormone expression in human granulosa cells. Fertil Steril. 2010; 94:1832-1839.

6. La Marca A, Volpe A. Anti-müllerian hormone (AMH) in female reproduction: is measurement of circulating AMH a useful tool? Clin Endocrinol (Oxf). 2006;64:603-610.

7. La Marca A, Sighinolfi G, Radi D, et al. Anti-Müllerian hormone (AMH) as a predictive marker in assisted reproductive technology (ART). Hum Reprod Update. 2010;16:113-130.

8. La Marca A, Giulini S, Tirelli A, et al. Anti-müllerian hormone measurement on any day of the menstrual cycle strongly predicts ovarian response in assisted reproductive technology. Hum Reprod. 2007;22:766-771.

9. Broer SL, Mol BW, Hendriks D, Broekmans FJ. The role of antimullerian hormone in prediction of outcome after IVF: comparison with the antral follicle count. Fertil Steril. 2009;91:705-714.

10. Teixeira J, Maheswaran S, Donahoe PK. Müllerian inhibiting substance: an instructive developmental hormone with diagnostic and possible therapeutic applications. Endocr Rev. 2001;22:657-674.

11. Tsepelidis S, Devreker F, Demeestere I, Flahaut A, Gervy C, Englert Y. Stable serum levels of anti-müllerian hormone during the menstrual cycle: a prospective study in normo-ovulatory women. Hum Reprod. 2007;22:1837-1840.

12. Pigny P, Merlen E, Robert Y, et al. Elevated serum level of antimüllerian hormone in patients with polycystic ovary syndrome: relationship to the ovarian follicle excess and to the follicular arrest. J Clin Endocrinol Metab. 2003;88:5957-5962.

13. Alemzadeh R, Kansra AR. New adolescent polycystic ovary syndrome perspectives. Minerva Pediatr. 2011;63:35-47.

14. Nardo LG, Gelbaya TA, Wilkinson H, et al. Circulating basal antiMüllerian hormone levels as predictor of ovarian response in women undergoing ovarian stimulation for in vitro fertilization. Fertil Steril. 2009;92:1586-1593.

15. Jee BC, Ku SY, Suh CS, Kim KC, Lee WD, Kim SH; the Seoul National University College of Medicine Assisted Reproductive Technology (SMART) Study Group. Serum Anti-Müllerian hormone and Inhibin B at ovulation triggering day can predict the number of immature oocytes retrieved in In Vitro Fertilization Cycles. J Korean Med Sci. 2008;23:657-661.

16. Gleicher N, Weghofer A, Barad DH. Discordances between follicle stimulating hormone (FSH) and anti-Müllerian hormone (AMH) in female infertility. Reprod Biol endocrinol. 2010;8:64.

17. Arabzadeh S, Hossein G, Rashidi BH, Hosseini MA, Zeraati H. Comparing serum basal and follicular fluid levels of anti-Müllerian hormone as a predictor of in vitro fertilization outcomes in patients with and without polycystic ovary syndrome. Ann Saudi Med. 2010;30: 442-447.
18. Barad DH, Weghofer A, Gleicher N. Comparing anti-Müllerian hormone $(\mathrm{AMH})$ and follicle-stimulating hormone (FSH) as predictors of ovarian function. Fertil Steril. 2009;91:1553-1555.

19. Nelson SM, Yate RW, Lyall H, et al. Anti-Müllerian hormone-based approach to controlled ovarian stimulation for assisted conception. Hum Reprod. 2009;24:867-875.

20. Shayya R, Chang RJ. Reproductive endocrinology of adolescent polycystic ovary syndrome. BJOG. 2010;117:150-155.

21. Van Rooij IA, Broekmans FJ, Scheffer GJ, et al. Serum antimüllerian hormone levels best reflect the reproductive decline with age in normal women with proven fertility. A longitudinal study. Fertil Steril. 2005;83:979-987.

22. Pigny P, Jonard S, Robert Y, Dewailly D. Serum anti-müllerian hormone as a surrogate for antral follicle count for definition of the polycystic ovary syndrome. J Clin Endocrinol Metab. 2006;91:941-945.

23. Eldar-Geva T, Margalioth E, Gal M, et al. Serum anti-müllerian hormone levels during controlled ovarian hyperstimulation in women with polycystic ovaries with and without hyperandrogenism. Hum Reprod. 2005;20:1814-1819.

24. Wachs DS, Coffler MS, Malcom PJ, Chang RJ. Serum anti-müllerian hormone concentrations are not altered by acute administration of follicle stimulating hormone in polycystic ovary syndrome and normal women. J Clin Endocrinol Metab. 2007;92:1871-1874.

25. te Velde ER, Pearson PL. The variability of female reproductive ageing. Hum Reprod. 2002;8:141-154.

26. Tehrani FR, Solaymani-Dodaran M, Hedayti M, Azizi F. Is polycystic ovary syndrome an exception for reproductive aging? Hum Reprod. 2010;25:1775-1781.

27. Weenen C, Laven JS, Von Bergh AR, et al. Anti-müllerian hormone expression pattern in the human ovary: potential implications for initial and cyclic follicle recruitment. Mol Hum Reprod. 2004;10:77-83.

28. Visser JA, de Jong FH, Laven JS, Themmen AP. Anti-Müllerian hormone: a new marker for ovarian function. Reproduction. 2006;131:1-9.

29. van Disseldorp J, Faddy MJ, Themmen AP, et al. Relationship of serum antimüllerian hormone concentration to age at menopause. J Clin Endocrinol Metab. 2008;93:2129-2134.

30. de Vet A, Laven JS, de Jong FH, Themmen AP, Fauser BC. Antimüllerian hormone serum levels: a putative marker for ovarian aging. Fertil Steril. 2002;77:357-362.

31. Fanchin R, Schonäuer LM, Righini C, Guibourdenche J, Frydman R, Taieb J. Serum anti-Müllerian hormone is more strongly related to ovarian follicular status than serum inhibin B, estradiol, FSH and LH on day 3. Hum Reprod. 2003;18:323-327.

32. Das M, Gillott DJ, Saridogan E, Djahanbakhch O. Anti-Mullerian hormone is increased in follicular fluid from unstimulated ovaries in women with polycystic ovary syndrome. Hum Reprod. 2008;23:2122-2126.

33. Dorgan JF, Spittle CS, Egleston BL, Shaw CM, Kahle LL, Brinton LA. Assay reproducibility and within-person variation of Müllerian inhibiting substance. Fertil Steril. 2010;94:301-304.

34. Falbo A, Rocca M, Russo T, et al. Serum and follicular anti-Mullerian hormone levels in women with polycystic ovary syndrome (PCOS) under metformin. J Ovarian Res. 2010;3:16.

35. Parco S, Novelli C, Princi T. Serum anti-Müllerian hormone and polycystic overy syndrome. A matter of methods? Minerva Pediatr. 2011. In press.
International Journal of General Medicine

\section{Publish your work in this journal}

The International Journal of General Medicine is an international, peer-reviewed open-access journal that focuses on general and internal medicine, pathogenesis, epidemiology, diagnosis, monitoring and treatment protocols. The journal is characterized by the rapid reporting of reviews, original research and clinical studies across all disease areas.

\section{Dovepress}

A key focus is the elucidation of disease processes and management protocols resulting in improved outcomes for the patient. The manuscript management system is completely online and includes a very quick and fair peer-review system. Visit http://www.dovepress.com/ testimonials.php to read real quotes from published authors. 